\title{
BORDES, LÍMITES Y FRONTERAS: NOTAS SOBRE LOS VIAJES EN MANSILLA, SAER Y AIRA
}

\author{
Nancy Fernández Della Barca*
}

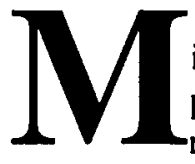

ientras que la incesante refiguración de los géneros discursivos, pone en crisis toda concepción taxonómica de la escritura, los registros literarios nos sitúan ante la ausencia de marcas que fijen rótulos. Tal vez pueda pensarse en la literatura como una serie de obsesiones

* Universidad Nacional de Mar del Plata, CELEHIS.

1 Clifford Geertz repara en las modificaciones de los saberes en relación al discurso o al pensamiento social de los "años recientes". visualizando dicho giro cultural en las producciones de autores como Michael Foucault, George Steiner. Norman Mailer. Jorge Luis Borges. Si hay alguna propiedad que conecten estos textos entre si es la tendencia a la interpretación que relativiza la líneas de clasificación. que. sin caer en un "eclecticismo petulante", reconocen en las áreas intelectuales. ángulos excéntricos. Geertz, siguiendo a Paul Ricoer, señala que la clave en la transición del texto, la escritura, el discurso a la acción, es el concepto de inscripción, es decir fijación del significado. los procesos del registro. Ver Clifford Geertz "Géneros confusos. La refiguración del pensamiento social" en: REYNOSO, Carlos (comp.) El surgimiento de la antropologia posmoderna. Barcelona: Gedisa, 1991. 
recurrentes: el amor, la muerte, la traición y el olvido. $Y$ el viaje. Desde Sarmiento y pasando por la Generación del 80', aún hoy la escritura argentina sigue explotando ese motivo con todo un acervo de cuestiones epistémicas, perceptuales y artísticas. El viaje condensa en la escritura, la ficción de un haber estado alli, de haber penetrado y haber sido penetrado por lo extraño de algún otro lugar. $^{2} \mathrm{Y}$ aunque suponga el olvido intermitente de la pertenencia, o los deslices discontinuos de la identidad, el yo se instala con goce en las tensiones del artificio retórico. La escritura de viajes - literatura, crónicas, antropologíagenera un efecto de autoconciencia y la transmisión de las impresiones -impresionarse/imprimir- supone el juego doble entre lo de afuera que me invade y la marca de lo propio. Envolverse o apropiarse implica el registro biográfico de la expêriencia, desplegar los espacios del yo, lo cual es relatado en Una excursión a los indios ranqueles -1872- de Lucio Mansilla. ${ }^{3}$ Mientras el viaje se proclama como misión política hacia los ranqueles, a la vez cede la prerrogativa que legitima al yo que escribe. Por tanto, la autobiografía va a operar como reaseguro social del sujeto que, mediante la escritura busca cifrar su rúbrica, su lugar.

Desde este diseño que conforma la figura del yo e inscribe el espacio egocéntrico, el género, sea carta, diario, memorias como instancias autobiográficas, se funde con la generación, expresión de hombres que procuran y construyen sus ancestros, su linaje. La charla instantánea del café, la ficción selectiva del recuerdo en cuanto a qué y a quién contar, fundan el ámbito de lo social y lo familiar, el lugar intermedio entre lo público y lo privado. Si la gran casa, el salón o el club materializan la mirada elitista del 80' configurando los espacios de la identidad, ${ }^{4}$ la frontera en Mansilla implica, aunque ilusoria, la ruptura con el pasado, el simulacro de la fisura genealógica. Para el general Mansilla, la "tierra adentro" no clausura el lugar reservado de la pertenencia sino que abre una grieta entre lo raro, lo distinto, lo negado y lo cercano, lo propio,

2 La relación entre percepción y escritura fue pensada desde um particular enfoque antropológico, por Clifford Geertz, cuya concepción de la etnografia prioriza la "puesta en escena. las intenciones y la autopresentación". La retórica de los etnógrafos derivan de un topos común. la elaboración de una sensibilidad en un lugar intrigante y a la vez extraño, en el Geertz desecha las perspectivas que privilegian el estudio de campo. la idea de "hecho en bruto". desconociendo los vínculos intrinsecos que los escritores estabelecen con la escritura, trama, narración o relato de los hechos. Ver GEERTZ, Clifford. El antropólogo como autor. Barcelona: Paidos. 1989.

3 MANSILLA, Lucio. Una excursión a los indios ranqueles. Buenos Aires: C.E.A.L.. 1987.

4 Para una visión cabal que integre las condiciones históricas. sociales y estéticas en lo que hace a la relación entre la escritura y la política. ver: JITRIK. Noé. El mundo del $80^{\circ}$. Buenos Aires: C.E.A.L., 1982. VIÑAS. David. Literatura argentina y realidad politica. Buenos Aires: C.E.A.L..1982. 
lo aceptado. El viaje es la recolocación de la disputa, la polémica, la exhibición y el entretenimiento a partir de un locus retórico digresivo, remanente en el desplazamiento físico e ideológico: la palabra exacerbada del verborrágico Mansilla emerge en los relatos de París o la frontera. Dicho de otro modo: en el territorio del desierto se marcan las huellas de los zapatos lustrosos de quien estuvo en París. Si se aleja del ámbito habitual, del hastío y la rutina, es para validarlo desde el descentramiento exótico. En este sentido, el viaje es tambien, explorar el pasado familiar ${ }^{5}$ construirse una filiación, simular la actualización del recuerdo. En este sentido, el narrador asume una relación intrínseca con el lenguaje porque la mirada y el impacto del mundo provocan el decir del yo. Hablar, relatar/se, supone construir la experiencia mediante la apropiación de la alteridad. Acto, gesto y palabra que se vuelve juego de profusión entre el frances, el ingles, el español y el vernáculo ranquelino.

Pero los itinerarios de Mansilla exceden los desplazamientos físicos dado que merodea por los bordes de la escritura y la lectura. Se viaja porque se leyó y se escribe lo que se mira. Los ojos de la civilización tiñen los actos de la conciencia. Ultimamente celebré un tratado de paz con ellos que el Presidente aprobó, con cargo de someterlo a Congreso.

Yo creia que siendo un acto administrativo no era necesario.

Qué sabe un pobre coronel de trotes constitucionales? Aprobado el tratado de esa forma. surgieron ciertas dificultades relativas a su ejecución inmediata. Esta circunstancia por un lado, por otro cierta inclinación a las correrias azarosas y lejanas; el deseo de ver con mis propios ojos ese mundo que llaman Tierra Adentro, para estudiar sus usos y costumbres, sus necesidades. sus ideas, su religión, su lengua e inspeccionar yo mismo el

5 Para Jean Starobinski. la narración autobiográfica es una conjunción de lo que Emile Benveniste habia reconocido por separado como el enunciado histórico y el discurso. El primero consistia en el "relato de los acontecimientos pasados". el segundo "presupone un locutor y un oyente, y en el primero, la intención de influir al otro en alguna forma”. La autobiografĩa es una "entidad mixta", dice Starobinski y uno de los elementos que mas posibilitan esta condición es. segün el crítico, el estilo. Dicho componente implica el presente def acto de escribir porque manifiesta la huella individual permitiendo hablar del valor autorreferencial. Remisión al momento de la escritura al yo actual, esto supone una "pantalla" entre la autenticidad del pasado y cl presente de la situación narrativa". Con la noción de autorreferencia, Starobinski posibilita pensar la autointerpretación, el pensamiento del pasado a partir del presente, principio de deformación. falsificación o divergencia cuyo sentido es sobre todo el de la singularización. Ver: STAROBINSKI. Jean. El progreso del intérprete en La relación critica (Psicoanálisis y literatura). Madrid: Taurus, 1974. 
terreno por donde alguna vez quizá tendrán que marchar las fuerzas que están bajo mis órdenes (Mansilla pp. 6-7).

La cita transmite un panorama del imaginario de época, a partir de la relación que se establece entre escritura, política y ciencia. Desde esta perspectiva, el objeto de la mirada se asimila al extrañamiento de la inmersión en el territorio de lo diferente, $o$ en la actitud que reduce lo real a lo inmediatamente observable, la concepción positivista que tiende a los valores de veridicción

Cuando me movi de Utratiquin.

The bright sun was"extinguish'd, and the stars

Did wander darkling in the eternal space.

La noche estaba bastante obscura. (Mansilla. p. 79)

$\mathrm{Y}$ dice mas adelante:

$Y$ pensando en esto. me engolfé en otras reflexiones. $y$ cuando la duda horrible y desgarradora me asaltó. recordé a Hamlet: ...To die, -to sleep...

To sleep! perchance to dream.

Me quedé soñando... (Mansilla, p.80).

El ingreso de la cultura funciona como señal de pertenencia, generando el doble efecto de la complicidad y la distancia en la recolocación del motivo shakespeareano. La meditación del príncipe dinamarqués se traslada al general que pone en escena su inmersión en el entorno vernáculo, para legitimar simultáneamente el sendero de retorno a Buenos Aires. En este sentido, el recorrido de Mansilla clausura la posesión del otro a partir de la traducción como acto fundacional de nombrar, rehacer, bautizar las cosas por el sello o la autoridad de su voz.

En El entenado (1883) de Juan José Saer, ${ }^{6}$ el viaje es recorrido inagotable en una doble instancia: la incursión por los mares desconocidos y los itinerarios erráticos del sentido. En la búsqueda del yo que escribe sin nombre hacia una lengua que pierde, olvida y reencuentra, se autorrefiere el cómo contar, como

6 SAER, Juan José. El entenado. México: Folios, 1983. 
relatar, donde lo vivido se condensa en lo visto. Los diez años de convivencia con los indios Colastiné, realizan en el narrador extranjero un borrado de la lengua de origen, origen que a la vez está planteado como ausencia. Sin nombre sin padre ni patria, el origen es ficción fundacional ${ }^{7}$ pero a la vez borrado incesante de las huellas, fugacidad que niega el punto fijo, la pertenencia o el arraigo; es la instancia que asume los vacíos del pasado y el presente de la escritura.

De esas costas vacias me quedó sobre todo la abundancia de cielo. (Saer, p.11)

Así se inicia la novela y así, desde una escritura lineal se representa la nada, se da cuenta de la inconsistencia del yo, se problematizan los presupuestos, la certidumbre como prejuicios de la conciencia y la razón. ${ }^{8}$ La fractura de la lengua, es decir, del modo en que se pone de manifiesto la aprehensión, la captura y expresividad de los objetos pierde el lazo con lo real, con el mundo externo, el entorno o la subjetividad. Desde los "bordes de esa negrura" emerge el fragmento perceptual. Entre el lenguaje y lo real reaparece la duda, lo incierto, el signo del interrogante. Desde esta perspectiva, el narrador relata su experiencia insistiendo en la inconsistencia de si mismo bajo el cielo de "ese azul

7 "Cuando alguien escribe yo escribe al yo en su escritura". Desde la perspectiva de ROSA. Nicolas. decir escribir yo funda la elocución como acto donde el sujeto asume la propiedad de su enunciado. El crítico reconoce en la autobiografia un régimem de valores ficcionales propuestos como remanencias no referenciales. Así. la interferencia repone la mediación entre la verdad de lo que se relata y la "verdad" de lo acontecido, lo cual permite el vinculo com la Historia. donde lo narrado y lo sucedido se disuelven en los operadores y efectos de la "verdad textual". Por otro lado. la autobiografia es un género descentrado en tanto que oscila entre escrituras del yo y las de registro taxonómico. Ver. ROSA, Nicolas. El arte del olvido (Sobre la autobiografia). Buenos Aires: Punto Sur, 1990.

8 Conceptos tales como sentido. verdad o realidad. adquieren el caracter de problema en la filosofia del lenguaje de Ludwig Wittgenstein. El reconocimiento de la designación de las palabras como el modo de uso. asume la complejidad del lenguaje desde la convención. la regla. la decisión. lo que socava el sentido univoco de la figura evocada. La tigura, para Wittgenstein, es paralela a los modos de expresión. mientras que el uso real lo es a las scrics infinitas. Fsta problematización del sentido se sustenta sobre la idea del lenguaje como laberinto. diseño enmarañado de "callejas y plazas". La proyección del lenguaje como entrecruzamiento de diversas funciones, asimila el tiempo al espacio. por cuanto descarta el criterio lijo y estable de las taxonomias que componen nuestro modelo. nuestra gramática. Desde esta perspectiva. la correspondencia entre nombres y objetos, es un problema de decisión. Ver. WITTGENSTEIN, Ludwig. Investigaciones filosóficas. Barcelona: Editorial Crítica. 1988. Del mismo autor Sobre la certeza. Barcelona: Gedisa. 1988. 
dilatado". De este modo, la escritura plantea el problema de la percepción provocando la extrañeza, el vacío, la negrura mediante la repetición de imágenes configuradas a partir de una misma marca enunciativa: el yo. Pero la cuestión perceptual ingresa como impresión instantánea y difusa de lo real y esto como el excedente, lo inalcanzable, la fuga ininterrumpida y la diferencia entre los límites mensurables del ego y lo infinito, lo no tangible de una esfera que se escapa, se disgrega. A su vez, el limite perceptual de la autoconciencia ingresa como su miniaturización: "éramos como hormigas en el centro de un desierto". Por otra parte, ese interrogante asume a la lengua como el desplazamiento fallido hacia lo real, hacia el sentido, como el viaje fisico y el interpretativo en el que se pierden, se reemplazan, se recuperan y modifican las claves de un código ya remoto. Limite, incertidumbre y vacio que vinculan desde la ausencia, a la lengua y la orfandad.

Cuando empecé a orientarme por la selva de e su lengua $y$ servirme toscamente de ella. lo que llevó tiempo, mas de una vez. curioso y aunque no de un modo directo los interrogué (Saer. 82).

En ese idioma, no hay ninguna palabra que equivalga a ser o cstar. La mas cercana significa parecer. Como tampoco tienen artículos. si quieren decir que hay un árbol o que un árbol es un árbol dicen parece árbol. Pero parece tiene menos el sentido de similitud que el de desconfianza. Es mas un vocablo negativo que positivo. Implica mas objeción que comparación. No es que remita a una imágen ya conocida sino que tiende. mas bien. a desgastar la percepción y' a restarle contundencia. La misma palabra que designa la apariencia, designa lo exterior. la mentira. los eclipses. el enemigo (Saer, p. 122).

En este sentido, el viaje cruza el desencuentro de lo conocido -la lenguay el encuentro paradójico que vuelve próximo lo extraño -la distancia exótica de los indios-.

Lo propio se olvida con el aprendizaje de la diferencia, la impregnación con la alteridad va a transformar el modo de aprehender el mundo, generando el descentramiento simultáneo del sujeto que relata. El tránsito por espacios nuevos o ajenos es la fuga que desvanece al sentido, lo oculta y vuelve inasible lo real, situando a los ojos del viajero la sola figura, lejana e inhaprensible de la lengua como límite. Este viaje a tierras imprevistas traza un mapa del lenguaje reticente a las presencias nítidas del sentido, desgastando la percepción contra 
el borde negro "de la verdad última de las cosas". Asi, la sensación de un universo incierto se corresponde con un idioma en el que dos objetos contrarios pueden llegar a nombrarse de la misma manera, como tambien la apariencia llega a prevalecer sobre la existencia o la verdad. El desplazamiento que opera en la novela es aleatorio con los itinerarios que recorren los espacios, la identidad del sujeto, las fronteras -la traducción-, y lo real.

Mientras que en Mansilla el acto de nombrar y traducir ratificaba aunque mas no fuera máscara de un hallazgo, en Saer las palabras que se aprenden encubren la fantasmagoría de la nada, de lo innominado. Los trayectos que en Mansilla perfilan la identidad del autor, buscan grabarse en la memoria de las generaciones futuras, el nombre propio del yo que descubre y conquista. Recorrido del desierto, el trazo de las huellas en la tierra genera la ficción o el mito del origen que en Saer se vuelve ausencia, orfandad donde las huellas del viajero se disuelven en las estelas de los mares. Si algo registra El entenado es el proceso de reapropiación de la lengua materna que pierde ante el impacto de la lengua diferente dando cuenta de la fugacidad, de lo errático.

En ambos textos, la escritura emerge como protagonista y Cesar Aira va establecer con ellos, un particular sistema de filiación. Recuperando la tradición de los viajes en Swift y Carroll, La liebre (1992), ${ }^{9}$ narra la curiosa travesía de un inglés que en el desierto argentino busca a un misterioso animal, la liebre legibreriana. Y como es habitual en la prosa de Aira desde Ema, la cauriva, el pasaje, el azar, la repetición y el desplazamiento son los operadores matrices de la escritura. Pero ante los ojos del viajero y sus dos acompañantes, el espacio se traza como dibujo sin forma ni contono, un desierto que aparece confuso en una serie de cruces a medida que se lo atraviesa. Los lugares, siendo constituidos por el sujeto, reclaman su mirada pero a la vez este es transfigurado por los espejismos de la extraterritorialidad, por la fuga incesante de las zonas recorridas. Así se intensifica la búsqueda de una Verdad oculta tras las sucesivas manifestaciones indescifrables. Desde esta perspectiva, es posible pensar en la estética de Aira como deconstrucción del "modelo" literario hegemónico, regido por criterios verosimiles. Es asi como la paradoja y el absurdo producen la ruptura con el canon literario decimonónico, en tanto La liebre es parodia, risa y carnaval del lenguaje artístico o el juego hiperbólico del delirio. La acción acumulada mas el sarcasmo de los motivos especulares -fuegos reflejándose en los miles de puntos móviles, grasa que sobre los cuerpos de los indios reduplican las imágenes, así como el gesto recurrente del bizqueo que las distorsionan-, potencian el desvio como representación y reenvían a la figura de la frontera en 
una doble perspectiva: la zona borrosa - el desierto - y los limites del sentido que marcarian como correlato metafórico el pasaje entre el adentro y el afuera del lenguaje, o la verdad que se explora en el suelo enigmático por donde se transita. El lugar, entonces, se genera como descentramiento de la unidad organizada ramificándose en dimensiones laterales, circulares y, como homenaje implícito a Borges, laberinticas. Pero la mirada transformadora del expedicionario inglés, se prolonga en un "cromatógrafo", implicando la metáfora del modo de ver, leer o captar lo real. El trabajo que Clarke realiza sobre esa "cajita metálica", asume el lugar de un sujeto que percibe y construye su propio sentido mediante una suerte de máquina de leer. Asimismo, el mirar tambien significa para el indio de la novela detenerse en el "cielo negro e inmutable", como si en los puntos de oscuridad, en la negrura del margen fuera posible fuera posible traslucir el sentido o lo legible del silencio. Asi, el viajar es inseparable del lenguaje, lo cual supone incursionar en la otra cultura. traducirla, impregnándose y repeliendo la alteridad. Desde este punto de vista, la polisemia desautoriza la palabra única, efecto que se produce cuando en la novela, Calfucurá se explaya sobre los muchos significados de la palabra ley; "atreverse", "sugerir", "extranjero", "saber", "palabra", "mapuche", palabras cuyas remisiones tienen el sesgo común del traspaso, la superación que reenvia a otro lado o cruza otra instancia. Si se juega con la pluralidad de sentidos con la potencialidad desbordante de significados, tambien se introduce el problema del límite representado como ley: la ley que posibilita distintas interpretaciones de un mismo término. La multiplicidad, por otro lado, genera ambigüedad desde los distintos usos del signo ligado a diferentes contertos. A esto hacen referencia las reiteradas alusiones a los sentidos "volátiles" de las palabras en mapuche, y la problematización con frecuencia explícita, de la configuración del lenguaje a partir del mundo o del entorno. Cuando hablo de lí-mite o frontera, pienso no solo en una figura que remita a espacios o zonas difusas sino tambien en los espacios que generan el desplazamiento y la repetición como operadores en la escritura -y el lenguaje-. Desde esta perspectiva, la traduccion supone un gesto lúdico que busca una clave de transformación y construcción del lazo entre signo, imágen y lo real ilusorio: palabra- acto que hace al objeto. Los modos de ver, referir y el sentido se proponen como limite entre la palabra y lo Real, funcionando a la vez como cruce polisémico. Así, la coexistencia de significados múltiples y aún disonantes entre si, ${ }^{10}$ lleva al problema de la traducción como juego de lenguaje proyectando lo real en lo poético.

10 Gilles Deleuze piensa el sentido como paradoja. a partir del devenir como relacion de simultaneidad que no soporta la distinción entre el antes y cl despues, es decir. descarta el sentido conuún de la lógica causal privilegiando la paradoja como la afirmación de "dos sentidos a la vez.". Ver. DELEUZE. Gilles. Lógica del sentido. Barcelona: Paidos. 1969 
Lo cierto es que uno de nuestros cuentos es sobre una liebre que correteaba por la llanura. huyendo de un caballo loco que se la queria comer: y cayó y cayó y cayó en la oscuridad y los ojos se le hinchaban y veia escenas que son una parte importante del cuento...(Aira, 173)

Viajar admite un encuentro con los otros relatos, las leyendas o, como diría Wittgenstein, con otras "formas de vida". Aquí, se trata del desplazamiento del sentido como lenguaje poético en tanto fábula que oficia como juego oblicuo que oculta al referente, envolviendo al sujeto en el entramado del lenguaje, moviendo al signo dentro de esta red. El relato de la liebre se instala como metáfora de búsqueda, captura y representación de un sentido evanescente, inaprehensible en torno a la mirada, los ojos, las escenas que evocan la representación, y el agujero o el vacío que anula la potencialidad referencial. Si con la fábula el indio pretende mostrar a Clarke el significado de aquello que todos buscan, como carrera que en su velocidad transmuta a las palabras detrás del sentido, si se espera develar la verdad prismática de la Liebre, la traducción ingresa desde sus aristas mas poéticas, desde el desvío o el implícito, por lo que

el sentido se constituye como ficción o simulacro. Entonces, situaciones como la reduplicación fantasmagórica de las imágenes fosforescentes, o la intermitencia y saturación comunicativa en el "arroyo lluvioso", tienden a ensamblarse con estas ideas asignando además a la liebre "legibreriana" la categoria simbólica de la interpretación, el ojo metafórico que veloz y fugaz, persigue como ventana, lo legible, lo real.

\section{RÉSUMEN}

En este trabajo, me propongo pensar la literatura de viajes como un amplio escenario de motivos, figuras y tramas que establecen las claves para una genealogía o filiación. Este sistema de "parentescos" literarios, pone de relieve la repetición y el desplazamiento. que problematizan la relación entre el lenguaje. lo real y el sujeto de escritura. Desde esta frontera confusa. los textos de Mansilia. Saer y Aira constituyen poéticas narrativas diferenciadas.

Palabras-chave: lenguaje, subjetividad, fronteras. 


\begin{abstract}
In this work I intend to think about travel literature as a wide scent of motives. images and plots wich establish the keys to a genealogy or filiation. This system of literary "kinships", emphasizes the repetition and displacement. that deal with the relationship between the language, the real and the subject of writing. From this confusing frontier. Mansilla, Saer and Aira's texts constitute differenciated narrative poetics.
\end{abstract}

\title{
REFERÊNCIAS BIBLIOGRAFICAS
}

AIRA. Cesar. La liebre. Buenos Aires: Emecé, 1991.

DELEUZE, Gilles. Lógica del sentido. Barcelona: Paidós. 1969.

GEERTZ. Clifford. El antropólogo como autor. Barcelona: Paidós, 1989.

Géneros confusos. La refiguración del pensamiento social, en: Carlos Reynoso (comp.)

El surgimiento de la antropologia posmoderna. Barcelona: Gedisa. 1991 . p. 63- 77. JITRIK, Noć. El mundo del 80'. Buenos Aires: C.E.A.L.. 1982.

MANSILLA, Lucio. Una excursión a los indios ranqueles. Bs.As.: C.E.A.L... 1982.

ROSA. Nicolás. El arte del olvido (sobre la autobiografia). Bs.As.: Punto Sur. 1990.

SAER. Juan José. El entenado. México: Folios, 1983.

STAROBINSKI, Jean. “EI progreso deł intérprete" , en: Jean Starobinski. La relación critica (psicoanálisis y literatura). Madrid: Taurus, 1974, p.65- 77.

VIÑAS, David. Literatura argentina y realidad politica. Bs.As: C.E.A.L.. 1982

WITTGENSTEIN. Ludwig. Investigaciones filosóficas. Barcelona: Editorial Crítica. 1988. 